\title{
"Testing for private information using trade duration models with unobserved market heterogeneity: The case of Banco Popular"
}




\section{UBREA \\ Institut de Recerca en Economia \\ Aplicada Regional i Pública \\ UNIVERSITAT DE BARCELONA}

\section{WEBSITE: www.ub.edu/irea/•CONTACT: irea@ub.edu}

The Research Institute of Applied Economics (IREA) in Barcelona was founded in 2005, as a research institute in applied economics. Three consolidated research groups make up the institute: AQR, RISK and GiM, and a large number of members are involved in the Institute. IREA focuses on four priority lines of investigation: (i) the quantitative study of regional and urban economic activity and analysis of regional and local economic policies, (ii) study of public economic activity in markets, particularly in the fields of empirical evaluation of privatization, the regulation and competition in the markets of public services using state of industrial economy, (iii) risk analysis in finance and insurance, and (iv) the development of micro and macro econometrics applied for the analysis of economic activity, particularly for quantitative evaluation of public policies.

IREA Working Papers often represent preliminary work and are circulated to encourage discussion. Citation of such a paper should account for its provisional character. For that reason, IREA Working Papers may not be reproduced or distributed without the written consent of the author. A revised version may be available directly from the author.

Any opinions expressed here are those of the author(s) and not those of IREA. Research published in this series may include views on policy, but the institute itself takes no institutional policy positions. 
In this paper, we attempt to assess the potential importance of different types of traders (i.e., those with public and private information) in financial markets using a specification of the standardized duration. This approach allows us to test unobserved heterogeneity in a nonlinear version based on a self-exciting threshold autoregressive conditional duration model. We illustrate the relevance of this procedure for identifying the presence of private information in the final days of trading of Banco Popular, the first bank rescued by the European Single Resolution Board.

JEL classification: C22, C41, D53, D82, G10, G12, G14.

Keywords: Conditional duration, threshold models, finite and infinite mixtures, private information, bank failure.

Jorge V. Pérez-Rodríguez: Department of Quantitative Methods. University of Las Palmas de Gran Canaria, Spain. Email: jv.perez-rodriguez@ulpgc.es

Emilio Gómez-Déniz: Department of Quantitative Methods. TiDES Institute. University of Las Palmas de Gran Canaria, Spain. Email: emilio.gomez-deniz@ulpgc.es

Simón Sosvilla-Rivero: Complutense Institute for Economic Analysis, Universidad Complutense de Madrid. Email: sosvilla@ccee.ucm.es

\section{Acknowledgements}

The authors are very grateful to Bolsas y Mercados Españoles for kindly providing the transaction durations dataset. The views expressed here are those of the authors and not necessarily those of the institution with which they are affiliated, nor those of Bolsas y Mercados Españoles. This paper is based on work supported by the Spanish Ministry of Economy and Competitiveness [grant ECO2016-76203-C2-2-P]. 


\section{Introduction}

Market prices aggregate and convey information, reacting to it and revealing it (see, e.g., Radner, 1979, and Grossman, 1981). On this view, market prices disclose the dispersed information held by investors about the underlying fundamentals of the economy. Economic theory in particular suggests that the presence of private information has important implications for financial markets. For instance, institutional investors, particularly those trading in individual stocks, possess firm-specific information which is not available to the general public; therefore, they are regarded as better informed and more sophisticated traders than individual investors (Albuquerque et al., 2009).

Financial market microstructure theories divide traders into uninformed (with no special informational advantages) and informed (with private information, see Glosten and Milgrom, 1985; Easley and O'Hara, 1987, among many others). For example, the presence of private information in financial markets has been documented not only in equity markets (see, e. g. Dev, 2013; and Levi and Zhang), but also in bond markets (see Brandt and Kavajecz, 2004; Green, 2004; Pasquariello and Vega, 2007; and Menkveld et al., 2008, among others) and foreign exchange markets (see, e. g., Lyons, 2001; and Evans and Lyons, 2008). ${ }^{1}$

In this paper we assess the presence of different categories of traders (i.e., those with public and those with private information), using financial trade duration models. Recent developments in the modelling of trade duration are able to model the behaviour of the different types of traders by introducing unobserved heterogeneity into duration models such as De Luca and Zuccolotto (2003), De Luca and Gallo $(2004,2009)$ and GómezDéniz and Pérez-Rodríguez (2016, 2017). To this end, these authors have proposed mixture distributions to account for the process of trading, considering in the model either a finite or an infinite number of traders with different probability laws.

More specifically, in this paper, we use a specification of the standardized duration which allows us to consider switching regimes in duration (so as to allow for fast and slow transacting periods or structural breaks in the trading process, because market conditions may have changed) but also to test unobserved heterogeneity (i.e., different probability laws for traders). In this regard, our model combines a nonlinear version based on a self-exciting threshold autoregressive conditional duration model (TACD) and a mixture of duration distributions. In our case, we propose a finite inverse Gaussian-TACD (FIGM-TACD) model, which assumes a finite mixture of an inverse Gaussian distribution with its reciprocal one (Gómez-Déniz and Pérez-Rodríguez, 2017), and two infinite mixtures also based on inverse Gaussian distributions (Gómez-Déniz and PérezRodríguez, 2016), given that these models allow us to consider non-monotonic hazard duration functions. ${ }^{2}$ We stress the relevance of this procedure for identifying different categories of traders (some of whom may possess public or private information) in the final trading days of Banco Popular, the first bank rescued by the European Single Resolution Board (SRB). ${ }^{3}$

Banco Popular was the sixth largest banking group in Spain before the SRB placed it under resolution. It was bought by Banco Santander as part of a rescue package in June

\footnotetext{
${ }^{1}$ Aslan et al. (2011) investigate the relationship between firm characteristics as captured by accounting and market data and a firm's probability of private information-based trade as estimated from trade data.

2 To our knowledge, Pérez-Rodríguez (2003) was the first paper to analyse the effect of financial trade durations on Spanish stocks. In particular, this author examined trading durations of Telefónica's stock using tick data.

${ }^{3}$ Later, on 23 June 2017, although the ECB declared Banca Popolare di Vicenza and Veneto Banca as 'failing or likely to fail', the SRB decided that resolution action was not warranted for these banks. These banks were wound up under national proceedings launched by the Italian authorities.
} 
2017. The decision was made after the European Central Bank (ECB) detected a stressed liquidity situation and considered that Banco Popular was "failing or likely to fail" on June 6 2017. The SRB and the Spanish National Resolution Authority decided on June 7 2017 that the sale was in the public interest, since it protected all depositors of Banco Popular and avoided adverse effects on financial stability and the real economy. The perceived lack of transparency regarding the SRB's treatment of Banco Popular has prompted a rash of litigation from both bondholders and shareholders.

The paper is organized as follows. Section 2 briefly surveys the literature on autoregressive conditional duration (ACD) models. Section 3 presents the econometric methodology for modelling the unobserved heterogeneity with a finite mixture. Section 4 reports the empirical results. Finally, Section 5 offers some concluding remarks.

\section{Financial duration models}

High-frequency financial transaction data provide researchers with unprecedented opportunities to study the evolution of financial asset prices at the transaction-bytransaction frequency. The intraday trading process has been modelled using the ACD model (Engle and Russell, 1998) and its extensions such as the logarithmic ACD (Bauwens and Giot, 2000), threshold autoregressive processes (Zhang et al., 2001; TACD), the Markov switching ACD model (Hujer et al., 2002; Calvet and Fisher, 2008; Chen et al., 2013) or the Box-Cox ACD which encompasses most specifications in the literature (Fernandes and Grammig, 2006). Stochastic conditional duration models have also been proposed (Bauwens and Veredas, 2004), as has the stochastic volatility duration model (Ghysels et al., 2004; SVD), among others.

These models have been estimated using different choices of duration distributions. The simplest distributional assumptions for conditional excess durations are the Exponential and Weibull distributions (Engle and Russell, 1998). Today, however, several choices of standardized financial duration distributions are available for estimating parameters of ACD models: for example, generalized Gamma (Lunde, 1999), Burr (Grammig and Maurer, 2000), or Birnbaum-Saunders (Bhatti, 2010), among others. Also, tests based on ACD parameters developed to test the innovation distribution of ACD specifications have been derived by gauging the distance between the parametric density and hazard rate functions implied by the duration process and their nonparametric estimates (Fernandes and Grammig, 2005), the density forecast evaluation technique (Bauwens et al., 2004) or the use of spectral density when testing for the so-called ACD effects, and for evaluating the adequacy of ACD models (Duchesne and Pacurar, 2008).

However, the above models do not account for the unobserved heterogeneity. Statistically, it is well known that duration analysis produces incorrect results if unobserved heterogeneity is ignored because it has serious consequences for parameter estimation (i.e., they may be quite sensitive to the presence of unobserved heterogeneity). In financial terms, following De Luca and Zuccolotto (2003), for example, unobserved heterogeneity can be caused by the differences across trading conditions (i.e., different degrees of information, as well as different attitudes toward risk, budget constraints, and so on), which are not readily captured by covariates (observed heterogeneity). The link between statistical and financial aspects in a set of distributional assumptions is based on financial market microstructure theories (which divide traders into informed and noninformed). In fact, the assumption of an interaction between agents, informed traders who possess private information. and liquidity traders whose information set is publicly available (O'Hara, 1995; and Ghysels, 2000), suggests that financial durations may obey 
different probability laws. Furthermore, there are many reasons for believing that arrival rates for informed and uninformed agents exhibit temporal dependence, with each having its own distinct pattern. In this regard, Dávila and Parlatore (2019) recently found that stocks with more volatile prices are likely to be less informative and that an increase in the precision of investors' private signals about the fundamental increases price informativeness.

In this context, the distribution of duration can be assumed to derive from a mixture of distributions. Authors like De Luca and Zuccolotto (2003), De Luca and Gallo (2004, 2009) and Gómez-Déniz and Pérez-Rodríguez $(2016,2017)$ have proposed a mixture of distributions to characterize the trading process. This allows us to take into account the unobserved heterogeneity (different trading conditions, traders, etc.) in the context of ACD models. For example, in the De Luca and Zuccolotto (2003) and De Luca and Gallo (2004, 2009) models, the simplest formulation is the mixture of exponential distributions, which can be a finite mixture (if traders are assumed to be divided into a finite number of groups) or an infinite mixture (when each trader is considered to have their own behaviour). More recently, Gómez-Déniz and Pérez-Rodríguez (2016, 2017) proposed finite and infinite mixtures of inverse Gaussian distributions, which accommodate the non-exponential and non-monotonic hazard functions.

\section{Unobserved heterogeneity and the threshold ACD model}

Engle and Russell's ACD models have been successful in modelling financial data that arrive at irregular intervals.

The ACD model was developed by Engle and Russell (1998). These authors specify a model for the duration $x_{i}=t_{i}-t_{i-1}$, where $t_{i}$ is the time for period $i$. This model can be easily formulated in terms of the expected conditional duration for the $i$-th trade: $\psi_{i}=E\left[x_{i} / x_{i-1}, \ldots, x_{1} ; \theta_{1}\right]$, where $x_{i}=\psi_{i} \varepsilon_{i}$. Therefore, $\frac{x_{i}}{\psi_{i}} \equiv \varepsilon_{i} \sim$ iid $D\left(\theta_{2}\right)$, where $D$ is a general distribution defined within the interval $(0, \infty)$ with $E\left[\varepsilon_{i}\right]=1 . \psi_{i}$ can be expressed as a linear function of past durations and conditional durations and is called the conditional duration. Hence, the $\operatorname{ACD}(p, q)$ model can be written as:

$$
\psi_{i}=\omega+\sum_{j=1}^{p} \alpha_{j} x_{i-j}+\sum_{j=1}^{q} \beta_{j} \psi_{i-j}
$$

where $\omega \geq 0, \alpha_{j} \geq 0$ and $\beta_{j} \geq 0$ for all $j$. Although not necessary, these sign restrictions are usuful to ensure the positivity of $\psi_{i}$ in the estimation.

\subsection{Fast and slow transacting periods: TACD}

Zhang et al. (2001) showed that simple TACD models can improve the analysis of stock transaction durations. Their model allows us to account for structural breaks in the trading process.

A simple two-regime $\operatorname{TACD}(2 ; \mathrm{p}, \mathrm{q})$ model for $x_{i}$ can be written as: 


$$
x_{i}= \begin{cases}\psi_{i} \varepsilon_{1 i} & \text { if } x_{i-d} \leq r \\ \psi_{i} \varepsilon_{2 i} & \text { if } x_{i-d}>r\end{cases}
$$

where $d$ is a positive integer, $x_{i-d}$ is the threshold variable, $r$ is a threshold, and

$$
\psi_{i}= \begin{cases}\omega_{10}+\sum_{j=1}^{p} \alpha_{1 j} x_{i-j}+\sum_{j=1}^{q} \beta_{1 j} \psi_{i-j} & \text { if } x_{i-d} \leq r \\ \omega_{20}+\sum_{j=1}^{p} \alpha_{2 j} x_{i-j}+\sum_{j=1}^{q} \beta_{2 j} \psi_{i-j} & \text { if } x_{i-d}>r\end{cases}
$$

where $s$ denotes the regime, and the parameters restrictions are $\omega_{s 0}>0, \alpha_{s j}>0$ and $\alpha_{s j}$ and $\beta_{s j}$ satisfy the conditions of the ACD model for $s=1,2$. The innovations $\left\{\varepsilon_{1 i}\right\}$ and $\left\{\varepsilon_{2 i}\right\}$ are two independent i.i.d. sequences.

\subsection{Trading process and unobserved heterogeneity}

\subsubsection{The finite-inverse Gaussian threshold ACD model (FIGM-TACD)}

Following Gómez-Déniz and Pérez-Rodríguez (2017) we use the finite mixture of inverse Gaussian model (FIGM) to estimate unobserved heterogeneity in the context of ACD models. This model allows us to account for two types of traders; i.e., liquidity and informed agents, with possible different duration times.

The conditional density of the FIGM-TACD model can be written as:

$$
f\left(x_{i} \mid \psi_{i}\right)=\frac{1}{\psi_{i}} \frac{\gamma \psi_{i}+\phi x_{i}}{\theta+\gamma} \sqrt{\frac{\lambda \psi_{i}}{2 \pi \phi x_{i}^{3}}} \exp \left[-\frac{\lambda}{2} \frac{\left(\phi x_{i}-\theta \psi_{i}\right)^{2}}{\phi \psi_{i} x_{i} \theta^{2}}\right] \text {, }
$$

where $\phi \equiv E(X)=\theta\left[1+\frac{\theta^{2}}{\lambda(1+\gamma)}\right]$. Note that $\gamma$ is the unobserved heterogeneity parameter, and represents the existence of two types of traders with different probability laws. This parameter is linked to the probability that the trade is immediately initiated in the market (no initial knowledge about the market is required), $(1-p)$ where $p=\theta /(\theta+\gamma)$. When $p=1, \gamma=0$, indicating that there is no unobserved heterogeneity. The absence of this unobserved heterogeneity may be related to the presence of low information flow (and, maybe, agents using only public information). However, when there is unobserved heterogeneity, $p \rightarrow 0$. A high value of $1-p$ could imply high information flow. This result may indicate that there are traders with different probability laws and, therefore, with different information about the stock (e.g., traders who might have both private and public information $)^{4}$. Note that, given their superior information, informed traders have the incentive to trade a large quantity of the stock at a fixed price as suggested by Easley and O'Hara (1987), Easley and O'Hara (1992) and Lee et al.

\footnotetext{
${ }^{4}$ Zhang et al. (2001) find evidence that fast transacting regimes are associated with agents trading based on private information.
} 
(1993); therefore, the likelihood of informed trading is positively correlated with trading volume and fast transacting periods.

The logarithm of the likelihood for the $i$-th observation can be written as:

$$
\begin{aligned}
\ell_{i}= & -\log \psi_{i}+\log \left(\gamma \psi_{i}+\phi x_{i}\right)-\log (\gamma+\theta)-\frac{\lambda}{2} \frac{\left(\phi x_{i}-\theta \psi_{i}\right)^{2}}{\phi \psi_{i} x_{i} \theta^{2}} \\
& +\frac{1}{2}\left[\log \lambda+\log \psi_{i}-\log (2 \pi)-\log \phi\right]-\frac{3}{2} \log x_{i}
\end{aligned}
$$

This model can be estimated by maximum likelihood and by using numerical methods such as BFGS.

\subsubsection{Mixture exponentials and threshold ACD models}

Another way to include unobserved heterogeneity into the modelling of trade durations is to consider infinite mixtures. In this section, we use two models proposed by Gómez-Déniz and Pérez-Rodríguez (2016), which extend the exponential mixtures of De Luca and Zuccolotto (2003).

First, we consider an exponential duration model with an inverse scale parameter and unobserved heterogeneity and extend the model to the case of the Erlang distribution (a special case of the gamma distribution which also includes the exponential one). The exponential distribution is generally used when the practitioner wants to model the survival times of items. It is known that the survival function of the exponential distribution with an inverse scale parameter (failure rate) $\theta \in \Theta>0$ is given by $S(t / \theta)=\exp (-t / \theta)$. Although the exponential model may be exact within a group of items, the hazard rate parameter frequently varies randomly across groups of items, reflecting some kind of heterogeneity in the population of items.

If we allow that $\Theta$ follows a distribution function $G(\theta)$ we have the following unconditional (mixture) survival function:

$$
S(t)=\operatorname{Pr}(T>t)=\int_{0}^{\infty} \exp \left(-\frac{t}{\theta}\right) d G(\theta)
$$

Continuous mixtures of exponential variables have been studied by, among others, Jewell (1982), and several distributions for $G(\theta)$ have been considered. For example, Lindley and Singpurwalla (1986) discussed the gamma mixtures of exponential distributions. Nayak (1987) extended Lindley and Singpurwalla's results to the multivariate Lomax distribution. Roy and Mukherjee (1988) generalized Nayak's work and examined properties of the resulting multivariate distribution.

Many of the different models used in the statistical literature concerning duration models are based on a mixture of the exponential one. The probability density function (pdf) of the exponential distribution with mean $\theta>0$ is given by:

$$
f(x)=\frac{1}{\theta} \exp \left(-\frac{x}{\theta}\right), x \geq 0 .
$$

The conditional duration model based on this distribution has a pdf given by: 


$$
f\left(x_{i} \mid \psi_{i}\right)=\frac{1}{\psi_{i}} \exp \left(-\frac{x_{i}}{\psi_{i}}\right)
$$

from which the log-likelihood function for the i-th observation is given by:

$$
\ell_{i}=\log f\left(x_{i} \mid \psi_{i}\right)=-\log \psi_{i}-\frac{x_{i}}{\psi_{i}}
$$

It is well known that the behaviour of economic agents differs depending on the information they have. Thus, those who are well informed will sell if they realize that the market price of an asset is above its real value, or buy if they believe it to be below its real value. This difference in behaviour is only one example of the different elements that can differentiate an individual from another, making the group of individuals usually treated as a heterogeneous population and in which there may be elements of contagion. Formally, this heterogeneity is treated by means of a discrete or continuous mixture of distributions. Some tools for studying the presence of heterogeneity in exponential models of duration can be found in Chesher (1984) and Kiefer (1984). The following are some of the mixtures of exponential models developed and studied in the field of duration..

In the case of classic models, we use the Weibull and Generalized Gamma threshold ACD models. The density function we use for the Weibull (Engle and Russell, 1998) or W-TACD is:

$$
f\left(x_{i} \mid \psi_{i}\right)=\frac{\gamma}{x_{i}}\left(\frac{x_{i}}{\phi_{i}}\right)^{\gamma} \exp \left(-\left(\frac{x_{i}}{\phi_{i}}\right)^{\gamma}\right), \text { where } \phi_{i}=\psi_{i}\left[\Gamma\left(1+\frac{1}{\gamma}\right)\right]^{-1}
$$

and the logarithm of the duration model is written as:

$$
\ell_{i}=\sum_{i=1}^{N}\left[\log \gamma-\log x_{i}+\gamma \log \frac{x_{i}}{\phi_{i}}-\left(\frac{x_{i}}{\phi_{i}}\right)^{\gamma}\right]
$$

In this regard, the conditional model based on the gamma and generalized gamma distribution (proposed by Stacy (1962)) can be viewed as a mixture of the exponential model (Gleser (1989) and Korolev et al. (2017)). Recall that the generalized gamma distribution has the gamma and Weibull distribution as a special one. .

The Generalized Gamma (Bhatti, 2009), named GG-TACD, is written as:

$$
f\left(x_{i} \mid \psi_{i}\right)=\frac{\theta}{\phi \psi_{i} \Gamma(\gamma)}\left(\frac{x_{i}}{\psi_{i} \phi}\right)^{\gamma \theta-1} \exp \left(-\left(\frac{x_{i}}{\psi_{i} \phi}\right)^{\theta}\right), \text { where } \phi=\Gamma(\gamma) /\left[\Gamma\left(\gamma+\frac{1}{\theta}\right)\right]
$$

and its logarithm is:

$$
\ell_{i}=\sum_{i=1}^{N}\left[\log \theta-\log \Gamma(\gamma)+(\gamma \theta-1) \log x_{i}-\gamma \theta\left(\log \psi_{i}+\log \phi\right)-\left(\frac{x_{i}}{\psi_{i} \phi}\right)^{\theta}\right]
$$


Regarding mixture exponential duration models, we distinguish between finite and infinite mixtures. On the one hand, we use the finite mixture of De Luca and Zuccolotto (2003, FEXP-TACD) based on exponentials. The conditional density and logarithm of likelihood are written as:

$$
\begin{gathered}
f\left(x_{i} \mid \psi_{i}\right)=\left[\sum_{k=1}^{K} p_{k} \frac{1}{\lambda_{k}} \exp \left(-\frac{x_{i}}{\psi_{i} \lambda_{k}}\right)\right] \frac{1}{\psi_{i}} \\
\ell_{i}=\sum_{i=1}^{N} \log \left[\sum_{k=1}^{K} p_{k} \frac{1}{\lambda_{k}} \exp \left(-\frac{x_{i}}{\psi_{i} \lambda_{k}}\right)\right]-\sum_{i=1}^{N} \log \psi_{i}
\end{gathered}
$$

where $p_{k}>0$ are the mixing proportions such that $\sum_{k=1}^{K} p_{k}=1$, and $\sum_{k=1}^{K} p_{k} \lambda_{k}=1$ is also needed. Note that $p_{k}$ is the proportion of agents in group $\mathrm{k}$, and $\lambda_{k}$ is the instantaneous expected rate of transaction carried out by the agents belonging to the k-th group. For example, De Luca and Gallo (2004) consider that $p_{1}$ represents informed traders for $K=2$.

On the other hand, we use the infinite mixtures based on exponentials such as the model proposed by De Luca and Zuccolotto (2003, IEXP-TACD). Also, the conditional density and logarithm of likelihood are written as:

$$
\begin{gathered}
f\left(x_{i} \mid \psi_{i}\right)=\frac{\theta^{\theta+1}}{\psi_{i}}(\theta+1)\left(\theta+\frac{x_{i}}{\psi_{i}}\right)^{-(\theta+2)} \\
\ell_{i}=\sum_{i=1}^{N}\left[(\theta+1) \log \theta-\log \psi_{i}+\log (\theta+1)-(\theta+2) \log \left(\theta+\frac{x_{i}}{\psi_{i}}\right)\right],
\end{gathered}
$$

where $\theta$ is the unobserved heterogeneity parameter and represents the existence of infinite agents with different probability laws.

Following Gómez-Déniz and Pérez-Rodríguez (2016), in this paper we also consider as a mixing distribution the reciprocal of the inverse Gaussian distribution, which has been considered in the statistical literature as an alternative model to the classical inverse Gaussian distribution and in the discrete mixture when the data have large tails (see Gómez-Déniz and Calderín-Ojeda (2019). The reciprocal of the inverse Gaussian distribution has hardly ever been used by the statistical community. The expression

$$
g(z)=\frac{\gamma}{\sqrt{2 \pi z}} \exp \left(-\frac{(\gamma z-\delta)^{2}}{2 z}\right), z>0, \gamma>0, \delta>0
$$

is the probability density function (pdf) of the reciprocal of a random variable that follows an inverse Gaussian distribution with parameters $\gamma>0$ and $\delta>0$. That is, if $Y, Y>0$, is distributed according to an inverse Gaussian distribution with parameters $\gamma>0$ and $\delta>0$, then the random variable $\mathrm{Z}=1 / \mathrm{Y}$ follows the distribution given in (1). It is simple to see that the distribution belongs to the exponential family of distributions from which it is easy to obtain properties of the distribution such as its mean, which is given by: 


$$
E(Z)=\mu=\frac{1}{\gamma}\left(\delta+\frac{1}{\gamma}\right)
$$

The exponential-reciprocal inverse Gaussian (ERIG-TACD) distribution is easily obtained by mixing the exponential distribution with (1). The result is the following pdf:

$$
f\left(\varepsilon_{i}\right)=\int_{0}^{\infty} \frac{1}{\theta} \exp \left(-\frac{\varepsilon_{i}}{\theta}\right) g(\theta) d \theta=\frac{\gamma \exp (\gamma \delta)}{\phi\left(\varepsilon_{i}, \delta\right)} \exp \left(-\gamma \phi\left(\varepsilon_{i}, \delta\right)\right), \varepsilon_{i}>0
$$

where $\phi\left(\varepsilon_{i}, \delta\right)=\sqrt{\delta^{2}+2 \varepsilon_{i}}$. By compounding, it is obvious that the mean of this distribution is just (2). by

From (3) it is easy to obtain the conditional pdf of the duration model. This is given

$$
f\left(x_{i} \mid \psi_{i}\right)=\frac{\gamma \mu}{\psi_{i}} \frac{\exp \left\{\gamma\left[\delta-\phi\left(x_{i} \mu / \psi_{i}, \delta\right)\right]\right\}}{\phi\left(x_{i} \mu / \psi_{i}, \delta\right)},
$$

where the parameters $\gamma>0, \delta>0$. The logarithm of the likelihood of i-th observation is defined by:

$$
\ell_{i}=\log (1+\gamma \delta)-\log \gamma-\log \psi_{i}+\gamma\left[\phi\left(x_{i} \mu / \psi_{i}, \delta\right)\right]-\log \phi\left(x_{i} \mu / \psi_{i}, \delta\right)
$$

As in the model developed in Gómez-Déniz et al. (2012) where the gamma distribution was mixed with the inverse Gaussian distribution, a natural extension of the model above is the mixture of the gamma distribution with shape parameter $\sigma>0$ and inverse scale parameter $\theta>0$ with the RIG given in (1). The result is a closed distribution which depends on the modified Bessel function of the second type. This special function can be overcome by starting with $\sigma=2$, i.e., considering an Erlang distribution. Some computations provide the probability density function of this mixture model, which is given by:

$$
f\left(x_{i} \mid \psi_{i}\right)=\left(\gamma+\frac{1}{\phi\left(x_{i} \mu / \psi_{i}, \delta\right)}\right) \frac{\vartheta^{2} \gamma x_{i}}{\psi_{i}^{2}} \frac{\exp \left\{\gamma\left[\delta-\phi\left(x_{i} \mu / \psi_{i}, \delta\right)\right]\right\}}{2 \vartheta x_{i} / \psi_{i}+\delta^{2}}
$$

The main advantage of (5) with respect to (3) is that it can exhibit larger tails. It is called the Gamma-reciprocal inverse Gaussian (GRIG-TACD). The logarithm of the likelihood for i-th observation can be written as:

$$
\begin{aligned}
\ell_{i}= & 2\left(\log 2+\log \delta+\log \left(1+\frac{1}{\delta \gamma}\right)\right)-2 \log \psi_{i}+\gamma\left[\delta-\phi\left(x_{i} \mu / \psi_{i}, \delta\right)\right] \\
& -\log \psi_{i}-\log \gamma+\log \left(\gamma+\frac{1}{\phi\left(x_{i} \mu / \psi_{i}, \delta\right)}\right)-\log \left(\frac{2 x_{i} \vartheta}{\psi_{i}}+\delta^{2}\right)
\end{aligned}
$$

where $\vartheta=2 \mu$. 


\section{Empirical analysis}

\subsection{Data}

We use the transaction durations of a listed stock of the Spanish commercial bank named Banco Popular on 21 consecutive trading days from 9 May to 6 June, 2017. Data were obtained from Bolsas y Mercados Españoles and represent positive transaction durations. We have 68486 intraday observations without zeros. Figure 1 shows the timepath of the trade durations, but also their histogram and kernel density.

Figure 1. Trade duration, histogram and kernel density.

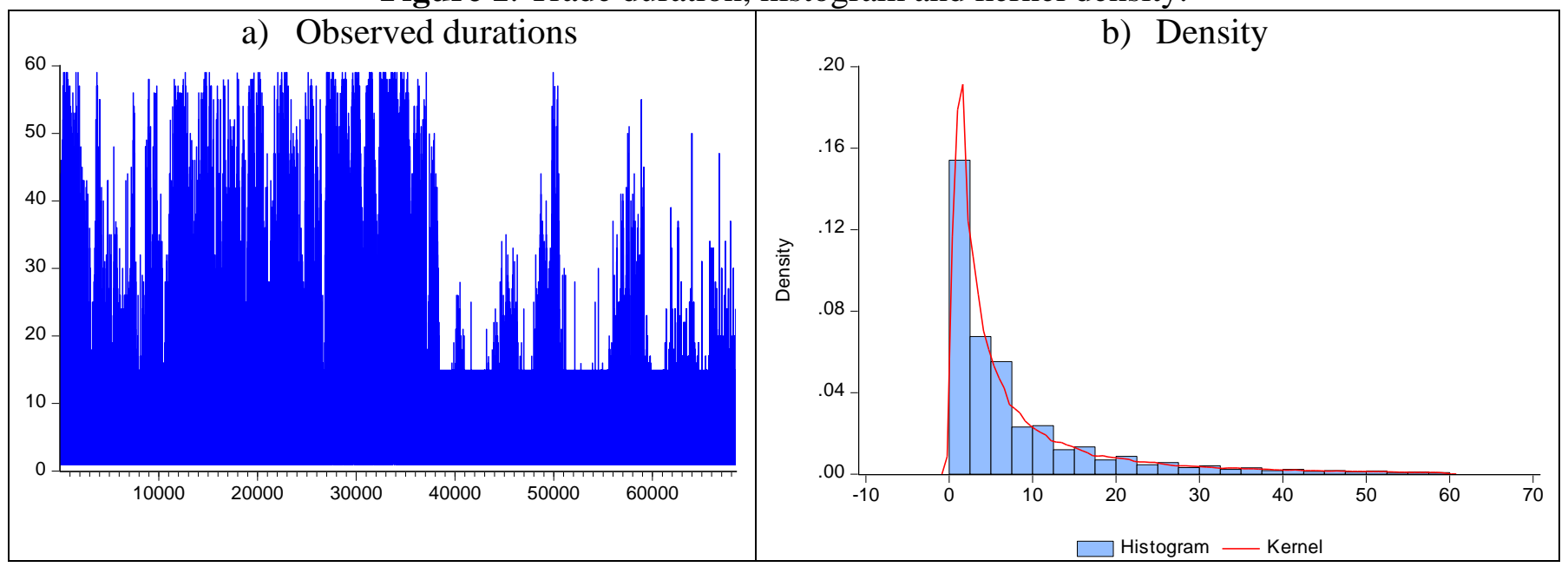

As we can see, duration shows a structural break after day 17, corresponding to May 31,2017 , and the histogram is clearly skewed to the right. Table 1 shows the descriptive statistics of the observed durations for the overall period and two subsamples. The first sample corresponds to the period May 9 up to May 30, 2017. It comprises 17 trading days. The second sample corresponds to the period May 31 up to June 6, 2017, and comprises four trading days.

Table 1. Descriptive statistics of observed durations.

\begin{tabular}{lccc}
\hline \hline & $\begin{array}{c}\text { Overall period } \\
\text { (May 9-June 6, 2017) }\end{array}$ & $\begin{array}{c}\text { First sample } \\
\text { (May 9-30, 2017) }\end{array}$ & $\begin{array}{c}\text { Second sample } \\
\text { (May 31 - June 6, 2017) }\end{array}$ \\
\hline Mean & 7.8428 & 11.0523 & 4.3871 \\
Median & 4.0000 & 6.0000 & 2.0000 \\
Maximum & 59.0000 & 59.0000 & 59.0000 \\
Minimum & 1.0000 & 1.0000 & 1.0000 \\
Std. Dev. & 10.1481 & 12.1549 & 5.6356 \\
Skewness & 2.3747 & 1.7179 & 3.5507 \\
Kurtosis & 9.0117 & 5.5935 & 20.6225 \\
& & & 496005.4 \\
Jarque-Bera & 167490.5 & 27416.1 & 0.00 \\
Probability & 0.00 & 0.00 & 32977 \\
& & & 35507 \\
Observations & 68484 & & \\
\hline \hline
\end{tabular}


From Table 1, we observe that mean durations are clearly lower in the second sample, but they also present some variability.

\subsubsection{Diurnal patterns and adjusted durations}

In this section, we introduce adjustments by removing the deterministic component of observed durations. That is, we employ 2159 positive adjusted durations. To do this, we have used a simple method to adjust the diurnal pattern of intraday trading activities. Figure 2 shows the diurnal patterns.

Figure 2. Transaction times measured in seconds from midnight.

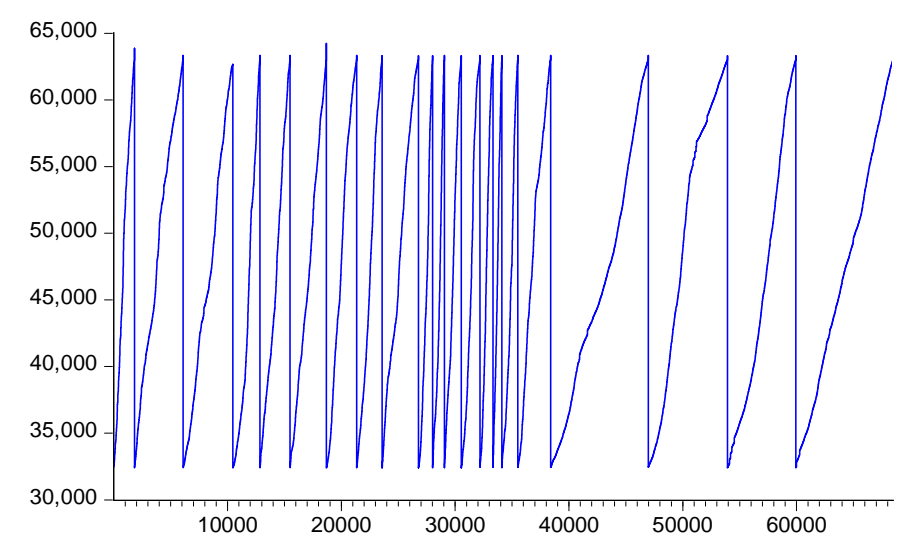

Figure 2 shows the time intervals from the market opening (9:00h) to the transaction time up to the market closing (17:35h). The vertical drops of the intervals signify the trading days. The diurnal pattern of trading activities is clearly seen. Besides, we also see that there are more durations/trading during the last four days until the end of trading on June 6, 2017.

There are many ways to remove the diurnal pattern of transaction durations. Engle and Russell (1998) and Zhang et al. (2001) use some simple exponential functions of time and Tsay (2005) constructs some deterministic functions of time of the day to adjust the diurnal pattern. Let $f\left(t_{i}\right)$ be the mean value of the diurnal pattern at time $t_{i}$, measured from midnight. Then, we define the adjusted duration as:

$$
\hat{x}_{i}=x_{i} / f\left(t_{i}\right)
$$

where $x_{i}$ is the observed duration between the $\mathrm{i}$-th and $(\mathrm{i}-1)$ th transactions. Following Tsay (2009), we construct $f\left(t_{i}\right)$ using two simple time functions. Define

$O\left(t_{i}\right)=\left\{\begin{array}{cc}\left(t_{i}-34200\right) & \text { if } t_{i}<43200 \\ 0 & \text { otherwise }\end{array}\right.$ and $C\left(t_{i}\right)=\left\{\begin{array}{cc}\left(61200-t_{i}\right) & \text { if } t_{i} \geq 43200 \\ 0 & \text { otherwise }\end{array}\right.$

where $t_{i}$ is the time of the ith transaction measured in seconds from midnight, and 34200 , 43200, and 61200 denote, respectively, the market opening, noon, and market closing times measured in seconds. Once the variables are made, we estimate by OLS the model: 


$$
\log \left(x_{i}\right)=\eta_{0}+\eta_{1} c\left(t_{i}\right)+\eta_{2} o\left(t_{i}\right)+v_{i}
$$

where $c\left(t_{i}\right)=O\left(t_{i}\right) / 10000$ and $c\left(t_{i}\right) C\left(t_{i}\right) / 10000$. Notably, all estimates of $\eta$ are statistically significant at the $5 \%$ significance level. Then, we construct the residual $\hat{v}_{i}$ and $\hat{x}_{i}=x_{i} / \hat{f}\left(t_{i}\right)=\exp \left(\hat{v}_{i}\right)$.

Figure 3 shows the adjusted trade duration. Compared with Figure 1, the diurnal pattern of the trade duration is to a large extent removed.

Figure 3. Adjusted trade duration.

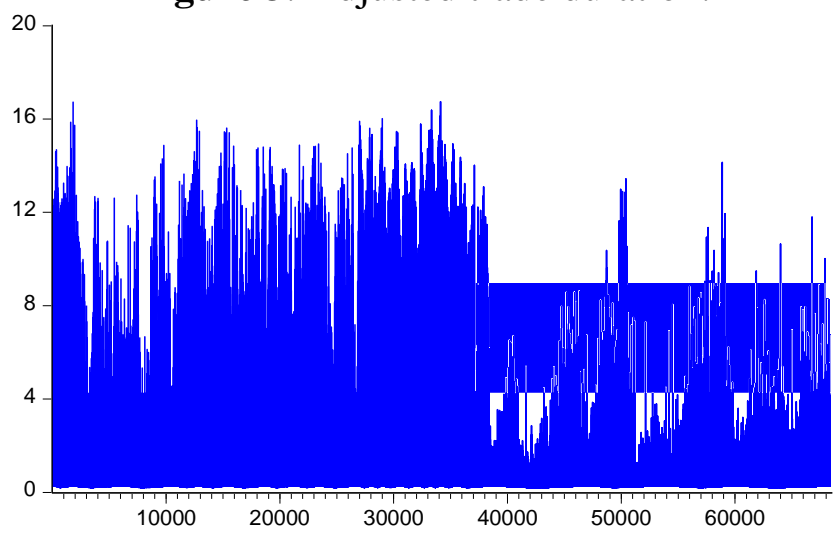

\subsubsection{Average 5-minute durations}

Now that the diurnal pattern has been addressed, we create another database formed by an average of 5-minute intraday observations. This new database comprises 2159 observations which are used to analyse durations empirically.

This number is obtained taking into account that we have $125^{\prime}$ intervals in 1 hour. Hence, 12 × 8 hours +7 intervals in the last hour $(17: 00-17: 35 \mathrm{~h})=103$ intervals during a day. In 21 days, we have $103 \times 21=2163$. The difference is due to the fact that there were four intervals without trading.

Figure 4. Average 5-minute trade duration.

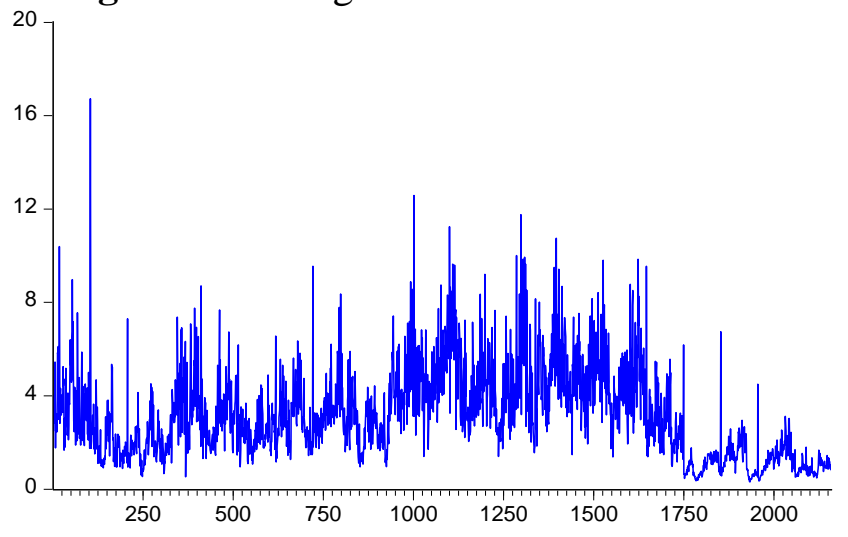

Table 2 shows results that maintain similar patterns as in Table 1, although the number of observations is considerably reduced.

Table 2. Descriptive statistics of average 5 minute durations. 


\begin{tabular}{lccc}
\hline \hline & $\begin{array}{c}\text { Overall period } \\
\text { (May 9-June 6, 2017) }\end{array}$ & $\begin{array}{c}\text { First sample } \\
\text { (May 9-30, 2017) }\end{array}$ & $\begin{array}{c}\text { Second sample } \\
\text { (May 31 - June 6, 2017) }\end{array}$ \\
\hline Mean & 3.1898 & 3.6942 & 1.2525 \\
Median & 2.8925 & 3.3794 & 1.1114 \\
Maximum & 16.7231 & 16.7231 & 6.7423 \\
Minimum & 0.3117 & 0.5309 & 0.3117 \\
Std. Dev. & 1.9234 & 1.8156 & 0.7202 \\
Skewness & 1.0694 & 1.1560 & 2.4236 \\
Kurtosis & 4.9674 & 5.5862 & 15.2454 \\
& & & \\
Jarque-Bera & 759.73 & 858.93 & 0.00 \\
Probability & 0.00 & 0.00 & 446 \\
Observations & 2159 & 1713 & \\
\hline \hline
\end{tabular}

\subsection{Empirical results}

The financial theory provides hardly any basis for discriminating between competing models, and so sample information must be used for this purpose. Therefore, in this section, we compare finite (FIGM-TACD) and infinite (ERIG-TACD and GRIG-TACD) with other classic and mixture models in the empirical literature on trade durations (see section 3.2.2).

Table 2 shows the results from the three models. In general, the $\operatorname{ACD}(1,1)$ specification can be used for each regime.

The first two models are classic models: TACD model with Weibull distribution (WTACD) and TACD with Generalized Gamma (GG-TACD). The finite mixtures are finite exponential TACD (FEXP-TACD) and the finite inverse Gaussian TACD (FIGMTACD). The infinite mixtures are infinite exponential TACD (IEXP-TACD), the model based on exponential and reciprocal inverse Gaussian (ERIG-TACD), and the Gammareciprocal inverse Gaussian (GRIG-TACD). For each model, we consider two columns. One of them represents the first regime (fast transaction period) and the second column shows the second regime (slow transaction period).

Model checking is investigated by analysing some statistics based on standardised durations, i.e., mean and standard deviation. On the other hand, if the ACD model is adequate $\left\{\hat{\varepsilon}_{i}\right\}$ should be an i.i.d. sequence of random variables. In particular, if the fitted model is adequate, both series $\left\{\hat{\varepsilon}_{i}\right\}$ and $\left\{\hat{\varepsilon}_{i}^{2}\right\}$ should have no serial correlation. In this connection, the Ljung-Box statistic can be used for both series. Therefore, $\mathrm{Q}(\mathrm{k})$ for $\mathrm{k}=10$ and 20 lags for autocorrelation (serial dependence) in the standardised residuals and their squares $\left(\mathrm{Q}_{2}(\mathrm{k})\right)$ which are shown in Table 2 . 
Table 3. Maximum likelihood parameter estimates of duration models.

\begin{tabular}{|c|c|c|c|c|c|c|c|c|c|c|c|c|c|c|}
\hline & \multicolumn{4}{|c|}{ Classic models } & \multicolumn{4}{|c|}{ Finite mixtures } & \multicolumn{6}{|c|}{ Infinite mixtures } \\
\hline & \multicolumn{2}{|c|}{ W-TACD } & \multicolumn{2}{|c|}{ GG-TACD } & \multicolumn{2}{|c|}{ FEXP-TACD } & \multicolumn{2}{|c|}{ FIGM-TACD } & \multicolumn{2}{|c|}{ IEXP-TACD } & \multicolumn{2}{|c|}{ ERIG-TACD } & \multicolumn{2}{|c|}{ GRIG-TACD } \\
\hline & $1^{\text {st }}$ regime & $2^{\text {nd }}$ regime & $1^{\text {st }}$ regime & \begin{tabular}{|c|}
$2^{\text {nd }}$ \\
regime
\end{tabular} & $1^{\text {st }}$ regime & $\begin{array}{c}2^{\text {nd }} \\
\text { regime }\end{array}$ & \begin{tabular}{|l}
$1^{\text {st }}$ \\
regime
\end{tabular} & \begin{tabular}{|c|}
$2^{\text {nd }}$ \\
regime
\end{tabular} & \begin{tabular}{|l|}
$1^{\text {st }}$ \\
regime \\
\end{tabular} & $\begin{array}{c}2^{\text {nd }} \\
\text { regime }\end{array}$ & \begin{tabular}{|l|}
$1^{\text {st }}$ \\
regime
\end{tabular} & $\begin{array}{c}2^{\text {nd }} \\
\text { regime }\end{array}$ & \begin{tabular}{|l}
$1^{\text {st }}$ \\
regime
\end{tabular} & \begin{tabular}{|c|}
$2^{\text {nd }}$ \\
regime
\end{tabular} \\
\hline$\gamma$ & -- & -- & $\begin{array}{l}167.04 \\
(685.1)\end{array}$ & $\begin{array}{l}19.587 \\
(642.9)\end{array}$ & -- & -- & $\begin{array}{c}2.2399 \\
(7.61)\end{array}$ & $\begin{array}{c}3.8902 \\
(5.30)\end{array}$ & -- & -- & $\begin{array}{c}178.665 \\
(10.4)\end{array}$ & $\begin{array}{c}133.71 \\
(1.74)\end{array}$ & $\begin{array}{l}0.9271 \\
(29.39)\end{array}$ & $\begin{array}{l}0.9388 \\
(29.02)\end{array}$ \\
\hline$\theta$ & -- & -- & $\begin{array}{l}0.2243 \\
(147.3\end{array}$ & $\begin{array}{l}0.6593 \\
(68.05)\end{array}$ & -- & -- & $\begin{array}{l}0.1623 \\
(10.47)\end{array}$ & $\begin{array}{c}0.4242 \\
(9.66)\end{array}$ & $\begin{array}{c}25820.6 \\
(46.7)\end{array}$ & $\begin{array}{c}210183.5 \\
(47.39)\end{array}$ & -- & -- & -- & -- \\
\hline$\delta$ & -- & -- & -- & -- & -- & -- & -- & -- & -- & -- & $\begin{array}{c}19102.45 \\
(106.9)\end{array}$ & $\begin{array}{c}3754.2 \\
(1.84)\end{array}$ & $\begin{array}{c}5.2480 \\
(6.46)\end{array}$ & $\begin{array}{c}5.6741 \\
(6.63)\end{array}$ \\
\hline$\lambda_{1}$ & -- & -- & -- & -- & $\begin{array}{c}0.0219 \\
(0.19)\end{array}$ & $\begin{array}{c}0.1604 \\
(1.57)\end{array}$ & $\begin{array}{c}1.0446 \\
(9.17)\end{array}$ & $\begin{array}{l}1.1161 \\
(7.15)\end{array}$ & -- & -- & -- & -- & -- & -- \\
\hline$p_{1}$ & -- & -- & -- & -- & $\begin{array}{l}0.7242 \\
(23.97)\end{array}$ & $\begin{array}{l}0.7734 \\
(14.98)\end{array}$ & -- & -- & -- & -- & -- & -- & -- & -- \\
\hline$\omega_{0}$ & $\begin{array}{c}-0.2548 \\
(-7.98)\end{array}$ & $\begin{array}{c}1.2364 \\
(6.14)\end{array}$ & $\begin{array}{c}-0.0130 \\
(-1.23)\end{array}$ & $\begin{array}{l}0.3608 \\
(61.02)\end{array}$ & $\begin{array}{c}-0.0025 \\
(-0.30)\end{array}$ & $\begin{array}{c}0.0724 \\
(1.92)\end{array}$ & $\begin{array}{c}-0.0139 \\
(-1.23)\end{array}$ & $\begin{array}{c}0.4518 \\
(6.19)\end{array}$ & $\begin{array}{c}-0.0076 \\
(-0.22)\end{array}$ & $\begin{array}{c}0.3188 \\
(2.54)\end{array}$ & $\begin{array}{c}-0.0075 \\
(-0.29)\end{array}$ & $\begin{array}{c}0.3678 \\
(3.74)\end{array}$ & $\begin{array}{c}-0.0159 \\
(-0.30)\end{array}$ & $\begin{array}{c}0.4332 \\
(1.61)\end{array}$ \\
\hline$\alpha_{1}$ & $\begin{array}{l}1.5842 \\
(62.15)\end{array}$ & $\begin{array}{l}2.5513 \\
(48.83)\end{array}$ & $\begin{array}{l}0.5357 \\
(37.88)\end{array}$ & $\begin{array}{l}0.1199 \\
(150.7)\end{array}$ & $\begin{array}{c}0.1213 \\
(4.45)\end{array}$ & $\begin{array}{c}0.0281 \\
(2.55)\end{array}$ & $\begin{array}{l}0.5636 \\
(17.67)\end{array}$ & $\begin{array}{c}0.1272 \\
(6.04)\end{array}$ & $\begin{array}{l}0.4710 \\
(17.15)\end{array}$ & $\begin{array}{c}0.1206 \\
(4.60)\end{array}$ & $\begin{array}{r}0.4709 \\
(6.23)\end{array}$ & $\begin{array}{c}0.1202 \\
(2.31)\end{array}$ & $\begin{array}{c}0.5892 \\
(4.33)\end{array}$ & $\begin{array}{l}0.1349 \\
(1.69)\end{array}$ \\
\hline$\beta_{1}$ & $\begin{array}{c}-0.0333 \\
(-1.91)\end{array}$ & $\begin{array}{l}0.7398 \\
(16.18)\end{array}$ & $\begin{array}{l}0.5243 \\
(78.36)\end{array}$ & $\begin{array}{l}0.8125 \\
(215.4)\end{array}$ & $\begin{array}{l}0.6118 \\
(12.27)\end{array}$ & $\begin{array}{l}0.8387 \\
(23.99)\end{array}$ & $\begin{array}{l}0.4879 \\
(19.35)\end{array}$ & $\begin{array}{l}0.7876 \\
(34.16)\end{array}$ & $\begin{array}{c}0.5768 \\
(26.7)\end{array}$ & $\begin{array}{l}0.8085 \\
(58.38)\end{array}$ & $\begin{array}{c}0.5769 \\
(8.92)\end{array}$ & $\begin{array}{l}0.8092 \\
(18.48)\end{array}$ & $\begin{array}{c}0.5509 \\
(6.18)\end{array}$ & $\begin{array}{c}0.8123 \\
(10.9)\end{array}$ \\
\hline $\begin{array}{c}\log \mathrm{L} \\
\text { Observations }\end{array}$ & $\begin{array}{r}-35 \\
2\end{array}$ & $\begin{array}{l}8.67 \\
59\end{array}$ & $\begin{array}{c}-2846.28 \\
2159\end{array}$ & & $\begin{array}{c}-4364.44 \\
2159\end{array}$ & & $\begin{array}{c}-2779.87 \\
2159\end{array}$ & & $\begin{array}{c}-4365.33 \\
2159\end{array}$ & & $\begin{array}{c}-4365.32 \\
2159\end{array}$ & & $\begin{array}{c}-4585.1 \\
2159\end{array}$ & \\
\hline $\begin{array}{l}\text { Average duration } \\
\text { Standard deviation }\end{array}$ & & & $\begin{array}{l}1.0038 \\
0.4222\end{array}$ & & $\begin{array}{l}3.7167 \\
1.5289\end{array}$ & & $\begin{array}{l}1.0122 \\
0.4309\end{array}$ & & $\begin{array}{l}1.0002 \\
0.4166\end{array}$ & & $\begin{array}{l}1.0002 \\
0.4166\end{array}$ & & $\begin{array}{l}0.8625 \\
0.3610\end{array}$ & \\
\hline
\end{tabular}




\begin{tabular}{|c|c|c|c|c|c|c|c|}
\hline $\mathrm{Q}(10)$ & $106.52[0.00]$ & $\begin{array}{c}11.60 \\
{[0.31]}\end{array}$ & $\begin{array}{c}13.51 \\
{[0.19]}\end{array}$ & $\begin{array}{c}16.81 \\
{[0.08]}\end{array}$ & $\begin{array}{c}10.57 \\
{[0.39]}\end{array}$ & $\begin{array}{c}10.53 \\
{[0.39]}\end{array}$ & $\begin{array}{c}10.55 \\
{[0.39]}\end{array}$ \\
\hline $\mathrm{Q}(20)$ & $194.35[0.00]$ & 20.36 & 23.56 & 25.89 & 19.02 & 18.97 & 19.13 \\
\hline & & $\begin{array}{c}{[0.48]} \\
3.68\end{array}$ & $\begin{array}{c}{[0.26]} \\
3.54\end{array}$ & $\begin{array}{c}{[0.17]} \\
3.67\end{array}$ & $\begin{array}{c}{[0.52]} \\
4.18\end{array}$ & $\begin{array}{c}{[0.52]} \\
4.17\end{array}$ & $\begin{array}{c}{[0.51]} \\
3.79\end{array}$ \\
\hline $\mathrm{Q}_{2}(10)$ & $1.32[0.99]$ & {$[0.96]$} & [0.96] & {$[0.96]$} & [0.94] & [0.94] & [0.96] \\
\hline $\mathrm{Q}_{2}(20)$ & $2.01[1.00]$ & $\begin{array}{c}4.75 \\
{[1.00]}\end{array}$ & $\begin{array}{c}4.57 \\
{[1.00]}\end{array}$ & $\begin{array}{c}4.65 \\
{[0.99]}\end{array}$ & $\begin{array}{c}5.28 \\
{[1.00]}\end{array}$ & $\begin{array}{c}5.27 \\
{[1.00]}\end{array}$ & $\begin{array}{c}4.85 \\
{[1.00]}\end{array}$ \\
\hline
\end{tabular}

Notes: $t$-values appear bin parentheses, and p-values in square brackets. In all models, we have chosen $q_{o}=0.5$ and $\hat{r}=x_{\langle 0.5\rangle}=2.8925$ seconds, in terms of maximum likelihood comparisons. 
For our stock transaction durations in the TACD models, we have chosen $d=1$. This is a reasonable choice, as trading activities tend to be highly serially correlated. For the threshold $r$, a simple approach is to use empirical quantiles. Following Tsay (2009), let $x_{\langle q\rangle}$ be the q-th quantile of the observed durations and we assume that $r \in\left\{x_{\langle q\rangle} / q=0.50,0.75,0.90,0.95,0.99\right\}$. For each candidate $x_{\langle q\rangle}$, we estimate the $\operatorname{TACD}(2 ; 1,1)$ model:

$$
\psi_{i}= \begin{cases}\omega_{10}+\alpha_{11} x_{i-1}+\beta_{11} \psi_{i-1} & \text { if } x_{i-1} \leq x_{\langle q\rangle} \\ \omega_{20}+\alpha_{21} x_{i-1}+\beta_{21} \psi_{i-1} & \text { if } x_{i-1}>x_{\langle q\rangle}\end{cases}
$$

and evaluate the log likelihood function of the model at the maximum likelihood estimates. Denote the resulting log-likelihood value by $\ell\left(x_{\langle q\rangle}\right)$. The threshold is then selected by $\hat{r}=x_{\left\langle q_{o}\right\rangle}$ such that $\ell\left(x_{\left\langle q_{o}\right\rangle}\right)=\max _{q}\left\{\ell\left(x_{\langle q\rangle}\right) / q=0.50,0.75,0.90,0.95,0.99\right\}$. In all models, we have chosen $q_{o}=0.5$ and $\hat{r}=x_{\langle 0.5\rangle}=2.8925$ seconds, in terms of maximum likelihood comparisons. Values of durations above $\hat{r}=x_{\langle 0.5\rangle}=2.8925$ indicate slow transaction periods and those below indicate fast transaction periods.

Classic models such as the W-TACD model show poor results. It has parameters which do not hold the positive restrictions, and for its part the Ljung-Box statistic for standardized residuals rejects the null hypothesis of zero autocorrelations. Therefore, this model is not adequate. However, GG-TACD shows a good statistical fit.

In terms of finite mixtures which identify two types of traders, ${ }^{5}$ FEXP-TACD $(K=2)$ model is less adequate than the FIGM-TACD in terms of Vuong's test $(-44.61, \mathrm{p}$ value $=0.00)$. We stress that the FEXP-TACD model suggests the existence of informed and uninformed traders. For example, results indicate that the proportions of agents representing informed traders in the first and second regimes are 0.72 and 0.77 respectively. They are high proportions in both regimes, although higher in the slow transaction regime than the fast regime. This may be reasonable taking into account that the analysed period represents the last days of Banco Popular's trading. On the other hand, the instantaneous expected rate of transaction carried out by the agents in this group is not statistically different from zero in either regime.

Now, focusing on the FIGM-TACD, we can say the following. Unobserved heterogeneity, $\gamma$, is statistically significant at the 5\% significance level in both regimes. It also indicates the presence of both uninformed and informed traders in the negotiation of our analysed stock, although we cannot distinguish between informed and uninformed traders as in FEXP-TACD following De Luca and Gallo (2004). Besides, in the second regime, the unobserved heterogeneity parameter is, generally, higher than in the first regime. It indicates that both these traders are more important in the slow transaction period than in the fast transaction period, where all traders could have had the same

\footnotetext{
${ }^{5} \mathrm{We}$ also fitted the FIGM-ACD model to the overall period. It is the FIGM adjusted separately for each regime taking into account the Quandt-Andrews unknown breakpoint. This was calculated under the null hypothesis with no breakpoints within 15\% trimmed data. In our case, observation 1714 (May 31, 2017) was identified using the maximum LR F-statistic. All parameters are statistically significant at the 5\% significance level and the logarithm of likelihood is -2792.14. Comparing FIGM-ACD and FIGM-TACD in terms of the maximum value of the log-likelihood function, FIGM-TACD has a better fit than the other models using Vuong's closeness test.
} 
information, given that the SRB's decision was known. Besides, the probability that trade is initiated immediately $(1-\hat{p}, \hat{p}=\hat{\theta} /(\hat{\theta}+\hat{\gamma}))$ is high in the two regimes ( 0.9 and 0.93 respectively), which indicates the high information flow and the rapid response of traders to negotiating in both regimes, although it is slightly higher in the second regime (slow transaction periods).

Finally, regarding the infinite mixtures, the results are similar to those of FEXPTACD in terms of the logarithm of likelihood. Therefore, although the infinite mixture summarizes a wide variety of agents or trading conditions and it allows for a complex unobserved heterogeneity, the estimated models do not perform better than their finite mixture counterparts. For example, IEXP-TACD and ERIG-TACD have similar values for the logarithm of likelihood, and both fit better than GRIG-TACD in terms of Vuong's test. The interpretation of these results may indicate that the number of different groups of agents in the market is not extensive and that two groups (as supposed by finite mixtures) may be enough. Finally, it should also be noted that heterogeneity parameters in the second regime (slow transaction periods) are, in general, greater than the first regime, indicating that both informed and uninformed traders may also act/predominate in this regime.

Overall, our results show two regimes in the Banco Popular's last days of trading, and that the slow duration regime showed higher unobserved heterogeneity than fast transaction periods. This behaviour could be taken as evidence of the presence of private information in both the regimes detected.

\section{Concluding remarks}

In this paper, we have attempted to assess the potential importance of different types of traders (i.e., traders with public or private information) in the final trading days of Banco Popular, the first bank rescued by the European Single Resolution Board. To this end, we applied a simple specification to estimate TACD by using a mixture of inverse Gaussian distributions recently proposed in the financial literature to test for the existence of unobserved heterogeneity, thus shedding light on the dynamics of the transaction arrival process.

Our results suggest the presence of informed traders with private information that was not available to the general public. We look forward to seeing more extended studies in future research when new case studies on SRB bank resolutions become available.

Finally, our approach may be applicable to other contexts with high levels of information dispersion - for instance, mergers and acquisitions or takeover bids.

\section{Acknowledgements}

The authors are very grateful to Bolsas y Mercados Españoles for kindly providing the transaction durations dataset. The views expressed here are those of the authors and not necessarily those of the institution with which they are affiliated, nor those of Bolsas $y$ Mercados Españoles.

\section{Funding}

This paper is based on work supported by the Spanish Ministry of Economy and Competitiveness [grant ECO2016-76203-C2-2-P]. 


\section{References}

Albuquerque, R., Bauer, G. H. and Schneider, M. (2009). Global private information in international equity markets. Journal of Financial Economics 94: 18-46.

Aslan, H., Easley, D., Hvidkjaer, S. and O'Hara, M. (2011). The characteristics of informed trading: Implications for asset pricing. Journal of Empirical Finance 18: 782-801.

Bauwens, L. and Giot, P. (2000). The logarithmic ACD model: An application to the bidask quote process of three NYSE stocks. Annales d'Economie et de Statistique 60: 117-150.

Bauwens, L. and Veredas, D. (2004). The stochastic conditional duration model: a latent factor model for the analysis of financial durations. Journal of Econometrics 119: 381-412.

Bauwens, L., Giot, P., Grammig, J., and Veredas, D. (2004). A comparison of financial duration models via density forecasts. International Journal of Forecasting 20: 589-609.

Bhatti, C.R. (2010). The Birnbaum-Saunders autoregressive conditional duration model. Mathematics and Computers in Simulation 80: 2062-2078.

Brandt, T. and Kavajecz, K. (2004). Price discovery in the U.S. treasury market: the impact of order flow and liquidity on the yield curve. Journal of Finance 59: 2623-2654.

Calvet, L. and Fisher, A. (2008). Multifractal volatility: Theory and pricing. Academic Press, London.

Chen, F., Diebold, F.X. and Schorfheide, F. (2013). A Markov-switching multifractal inter-trade duration model, with application to US equities. Journal of Econometrics 177: 320-342.

Chesher, A. (1984). Testing for neglected heterogeneity. Econometrica, 52, 4, 865-872.

Dávila, E. and Parlatore, C. (2019). Volatility and informativeness. Working Paper 25433, National Bureau of Economic Research, Cambridge, MA.

De Luca, G. and Gallo, G. M. (2004). Mixture processes for intradaily financial durations. Studies in Nonlinear Dynamics and Econometrics 8: 1-18.

De Luca, G. and Gallo, G.M. (2009). Time-varying mixing weights in mixture autoregressive conditional duration models. Econometric Reviews 28: 102- 120.

De Luca, G. and Zuccolotto, P. (2003). Finite and infinite mixtures for financial durations. Metron 61: 431-455.

Dev, P. (2013). Transfer of information by an informed trader. Finance Research Letters 10: 58-71.

Easley, D. and O'Hara, M. (1987). Price, trade size, and information in securities markets. Journal of Financial Economics 19: 69-90.

Easley, D. and O'Hara, M. (1992). Adverse selection and large trade volume. Journal of Financial and Quantitative Analysis 27: 185-208.

Easley, D., O'Hara, M. and Saar, G. (2001). How stock splits affect trading: A microstructure approach. Journal of Financial and Quantitative Analysis 36: 2551.

Engle, R.F. and Russell, J.R. (1998). Autoregressive conditional duration: A new model for irregularly-spaced transaction data. Econometrica 66: 1127-1162.

Evans, M. D. D. and Lyons, R. K. (2008). How is macro news transmitted to exchange rates? Journal of Financial Economics 88: 26-50.

Fernandes, M. and Grammig, J., (2006). A family of autoregressive conditional duration models. Journal of Econometrics 130: 1-23 
Ghysels, E. (2000). Some econometric recipes for high-frequency data cooking. Journal of Business \& Economic Statistics 18: 154-163.

Ghysels, E., Gouriéroux, C. and Jasiak, J. (2004). Stochastic volatility duration. Journal of Econometrics 119: 413-433.

Gleser, L.J. (1989). The gamma distribution as a mixture of exponential distributions. The American Statistician, 43, 2, 115-117.

Glosten, L. R., and Milgrom, P. (1985), Bid, ask, and transaction prices in a specialist market with heterogeneously informed agents. Journal of Financial Economics 14: $71-100$.

Gómez-Déniz, E., Calderín, E., Sarabia, J.M. (2013). Gamma-generalized inverse Gaussian class of distributions with Applications. Communications in Statistics: Theory and Methods. 42: 919-933.

Gómez-Déniz, E. and Pérez-Rodríuez, J.V. (2016). Conditional duration model and unobserved market heterogeneity of traders. An infinite mixture of non-exponentials. Colombian Journal of Statistics 39: 307-323.

Gómez-Déniz, E. and Pérez-Rodríguez, J.V. (2017). Mixture inverse Gaussian for unobserved heterogeneity in the autoregressive conditional duration model. Communications in Statistics: Theory and Methods 46: 9007-9025.

Gómez-Déniz, E.; Calderín-Ojeda, E. (2018). Properties and applications of the Poissonreciprocal inverse Gaussian distribution. Journal of Statistical Computation and Simulation, 88, 2, 269-289.

Grammig, J. and Maurer, K. O. (2000). Non-monotonic hazard functions and the autoregressive conditional duration model. Econometrics Journal 3:16-38.

Green, T. (2004). Economic news and the impact of trading on bond prices. Journal of Finance 59: 1201-1233.

Grossman, S. J. (1981). An introduction to the theory of rational expectations under asymmetric information. Review of Economic Studies 48: 541-559.

Hujer, R., Vuletic, S. and Kokot, S. (2002). The Markov switching ACD model. Finance \& Accounting Working Paper 90, Johann Wolfgang Goethe-University, Frankfurt.

Jewell, N. P. (1982). Mixtures of exponential distributions. The Annals of Statistics, 10, 479-484.

Kiefer, N.M. (1984). Simple test for heterogeneity in exponential models of duration. Journal of Labor Economics, 2, 4, 539-549.

Korolev, V.; Gorshenin, A. and Zeifman, A. (2017). Generalized gamma distributions as mixed exponential laws and related limits theorems. Proceedings 31st European Conference on Modelling and Simulation.

Lee, C. M. C., Mucklow, B. and Ready, M.J. (1993). Spreads, depths and the impact of earnings information: An intraday analysis. Review of Financial Studies 6: 345374.

Levi, S. and Zhang, X. (2014). Do temporary increases in information asymmetry affect the cost of equity? Management Science 61:354-371.

Lindley, D. V. and Singpurwalla, N. D. (1986) Multivariate distributicns for the reliability of a system of components sharing a common environment. Journal of Applied Probability, 23, 418-431.

Lunde, A. (1999). A generalized gamma autoregressive conditional duration model. Discussion Paper, Aalborg University, Aalborg.

Lyons, R. K. (2001). The Microstructure Approach to Exchange Rates. MIT Press, Boston. 
Menkveld, A., Sarkar, A. and van der Wel, M. (2008). Macro news, risk-free rates, and the intermediary: customer orders for $30 \mathrm{Y}$ treasury futures. Journal of Financial and Quantitative Analysis 47: 821-849.

Nayak, T. K. (1987). Multivariate Lomax distribution: properties and usefulness in reliability theory. Journal of Applied Probability, 24, 170-177.

O’Hara, M. (1995). Market Microstruture Theory, Basil Blackwell, Oxford.

Pasquariello, P. and Vega, C. (2007). Informed and strategic order flow in the bond markets. Review of Financial Studies 20: 1975-2019.

Pérez-Rodríguez, J.V. (2003). Intensidad de la actividad de negociación y volumen de las transacciones. Moneda y Crédito 217; 227-255.

Radner, R. (1979). Rational expectations equilibrium: Generic existence and the information revealed by prices. Econometrica 47: 655-678.

Stacy, E.W. (1962). A generalization of the gamma distribution. Annals of Mathematical Statistics, 33, 1187-1192.

Tsay, R. S. (2005). Analysis of Financial Time Series, 2nd edition, John Wiley, Hoboken, NJ.

Tsay, R. S. (2009). Autoregressive conditional duration models. In: Mills T. C. and Patterson K. (eds) Handbook of Econometrics, Vol. 2 (Applied Econometrics). Palgrave MacMillan, London: 1004-1024.

Zhang, M.Y., Russell, J.R. and Tsay, R.S. (2001). A nonlinear autoregressive conditional duration model with applications to financial transaction data. Journal of Econometrics 104: 179-207. 


\section{UBIREA}

Institut de Recerca en Economia Aplicada Regional i Pública

Research Institute of Applied Economics

\section{Universitat de Barcelona}

Av. Diagonal, $690 \cdot 08034$ Barcelona

WEBSITE: www.ub.edu/irea/ • CONTACT: irea@ub.edu 